\title{
Perivascular Epithelioid Cell Tumor in the Stomach
}

\author{
Sun Ah Shin · Jiwoon Choi \\ Kyung Chul Moon · Woo Ho Kim \\ Department of Pathology, Seoul National \\ University Hospital, Seoul, Korea \\ Received: August 15, 2016 \\ Accepted: September 16, 2016

\section{Corresponding Author} \\ Woo Ho Kim, MD, PhD \\ Department of Pathology, Seoul National University \\ College of Medicine, 103 Daehak-ro, Jongno-gu, \\ Seoul 03080, Korea \\ Tel: +82-2-740-8269 \\ Fax: +82-2-765-5600 \\ E-mail:woohokim@snu.ac.kr
}

Perivascular epithelioid cell tumors or PEComas can arise in any location in the body. However, a limited number of cases of gastric PEComa have been reported. We present two cases of gastric PEComas. The first case involved a 62-year-old woman who presented with a $4.2 \mathrm{~cm}$ gastric subepithelial mass in the prepyloric antrum, and the second case involved a 67-year-old man with a $5.0 \mathrm{~cm}$ mass slightly below the gastroesophageal junction. Microscopic examination revealed that both tumors were composed of perivascular epithelioid cells that were immunoreactive for melanocytic and smooth muscle markers. Prior to surgery, the clinical impression of both tumors was gastrointestinal stromal tumor (GIST), and the second case was erroneously diagnosed as GIST even after microscopic examination. Although gastric PEComa is a very rare neoplasm, it should be considered in the differential diagnosis of gastric submucosal lesions.

Key Words: Perivascular epithelioid cell neoplasms; Stomach neoplasms; HMB-45 protein, human; MART-1 antigen; Gastrointestinal stromal tumors
In the early 1990s, Pea et al. ${ }^{1}$ reported that renal angiomyolipomas demonstrated positive immunoreactivity for human melanoma black (HMB)-45, which recognize the premelanosome protein encoded by the PMEL gene. ${ }^{2}$ Subsequently, the same group asserted that cells of renal angiomyolipomas and clear cell tumors of the lung demonstrated similar morphology and had identical immunohistochemical profiles. ${ }^{3}$ Bonetti et al. ${ }^{4}$ proposed the term perivascular epithelioid cell to describe the aforemen-

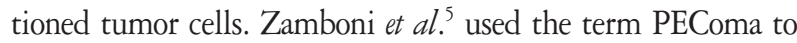
describe tumor containing perivascular epithelioid cells with immunoreactivitiy for melanocytic markers when they detected a clear cell "sugar" tumor arising in the pancreas. In 2002, the World Health Organization classified PEComa as a distinct disease entity, a mesenchymal neoplasm composed of distinctive cells that partly show an association with blood vessel walls and usually express melanocytic and smooth muscle markers. ${ }^{6}$

PEComa predominantly arises in the kidney, lung, falciform ligament, ligamentum teres, uterus, or gastrointestinal tract. ${ }^{7-9}$ PEComas located in the gastrointestinal tract predominantly affect the colon and small intestine, ${ }^{9-11}$ and only a limited number of cases of gastric PEComa have been reported in the English literature. Here, we present two cases of gastric PEComa encountered in our hospital.

\section{CASE REPORT}

The first patient was a 62-year-old woman. She underwent a routine check-up due to a minor injury to her foot. Elevated liver enzyme levels were noted, and subsequent abdomen ultrasonography revealed a submucosal mass in the stomach. She had neither signs of tuberous sclerosis complex nor any family history of it. An abdomen computed tomography image showed a 4.2$\mathrm{cm}$ subepithelial mass with broad base in the prepyloric antrum (Fig. 1A). Endoscopic ultrasound revealed a hypoechoic mass involving the proper muscle layer, and laparoscopic wedge resection of stomach was performed. Lymph node enlargement or peritoneal metastasis was not detected. The patient was discharged after the surgery without any complication.

On gross examination, the subepithelial mass measured $4.2 \times$ $3.2 \times 2.0 \mathrm{~cm}$ and demonstrated fleshy cut surface with a welldefined border (Fig. 1B). Microscopically, the tumor displayed a nested pattern of epithelioid tumor cells with abundant granular eosinophilic cytoplasm and round to oval nuclei (Fig. 1C). The nests were surrounded by thin walled capillaries and a radial arrangement of tumor cells was found around the vascular lumens. The tumor cells showed mild pleomorphism, but coagulation necrosis was not observed. The mitotic count was 1 in 50 high power fields (HPF). Lymphovascular or perineural invasion was 

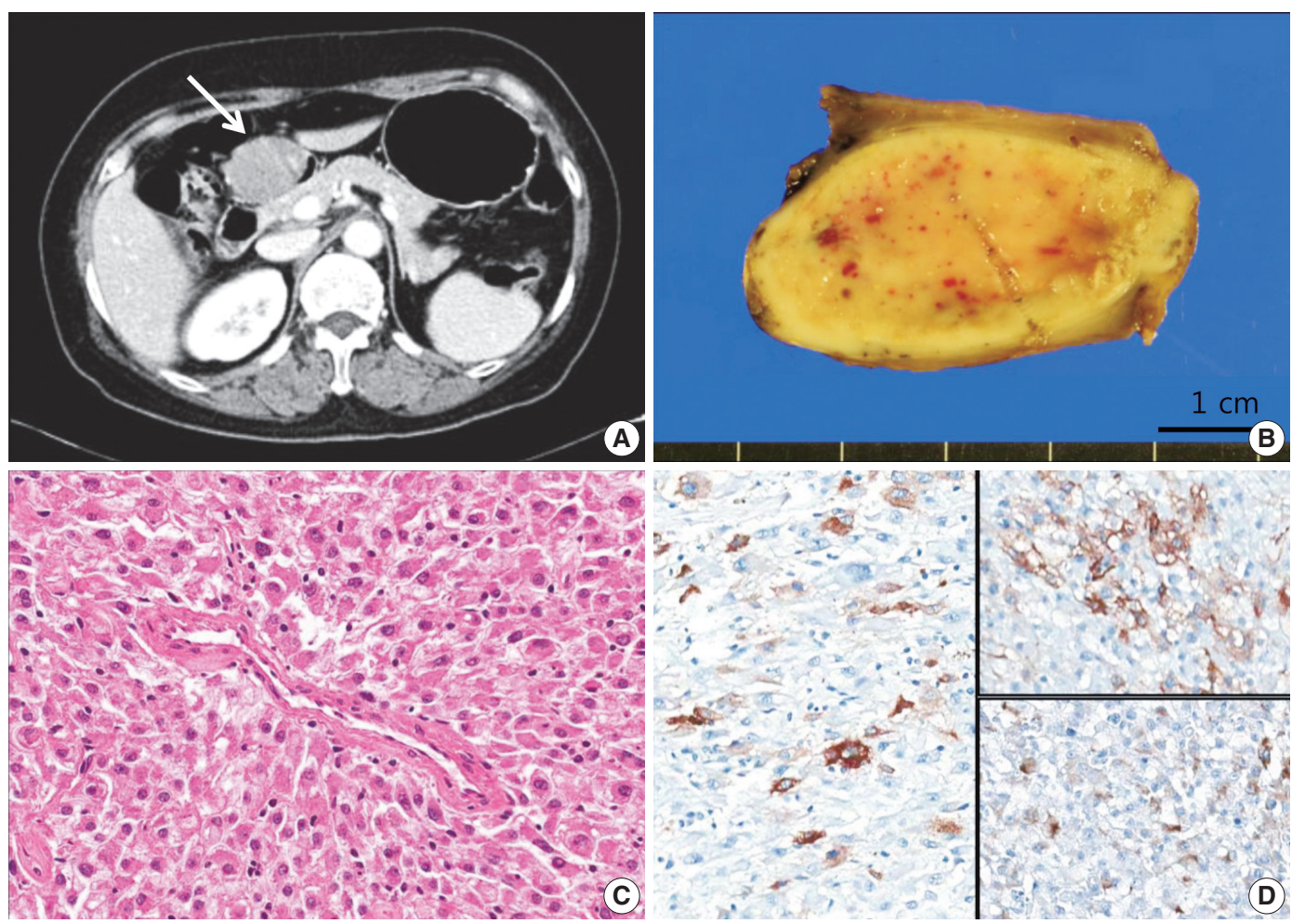

Fig. 1. Case 1. (A) Abdomen computed tomogragphy shows a 4.2-cm-sized mass (arrow) with broad base in the prepyloric antrum. (B) On gross examination, the mass shows fleshy cut surface with a well-defined border. (C) Microscopically, the tumor displays a nested pattern, and the tumor cells were epithelioid with abundant granular eosinophilic cytoplasm and round nuclei. (D) Immunohistochemistry shows positive staining for human melanoma black 45 (left), smooth muscle actin (upper right), and desmin (lower right).

not found. The tumor was focally positive for human melanoma black 45 (HMB-45), smooth muscle actin (SMA), and desmin (Fig. 1D), and negative for Melan A, vimentin, CD117, CD34, S100, pancytokeratin, and transcription factor E3 (TFE3). The Ki-67 labeling index was $1 \%$.

The second case was detected when we evaluated the expression of melanocytic and smooth muscle markers on our 343 gastrointestinal stromal tumor (GIST) cases. The patient was a 67-year-old man who was transferred to our hospital for further evaluation of low hemoglobin levels. Endoscopic examination revealed a 5.0-cm ulcerofungating mass with spontaneous bleeding below the gastroesophageal junction, and a subtotal gastrectomy was performed. The subepithelial mass measured 5.0 04.7 $\times 1.6 \mathrm{~cm}$ (Fig. 2A). Microscopically, the lesion was composed of radially arranged epithelioid cells, involving mucosa to subserosa (Fig. 2B, C). The nuclei showed marked pleomorphism and the mitotic counts were high (45/50 HPF). Direct sequencing of the KIT and PDGFRA genes revealed no mutations. The tumor showed focal positivity for SMA (Fig. 2D) and faint positivity for CD117. Thus, the tumor was initially diagnosed as epithelioid GIST. However, during the re-evaluation of GIST cases with melanocytic markers, this case was positive for Melan- $\mathrm{A}$ as well as SMA, and therefore, the diagnosis was revised to PEComa. The patient did not receive any further treatment, and he did not show any evidence of recurrence for 7 years.

\section{DISCUSSION}

PEComa involving the gastrointestinal tract is rare, and the most common site within the gastrointestinal tracts is the colon. ${ }^{9-11}$ Only six cases of gastric PEComa have been reported in English literature, ${ }^{9,12-15}$ and two cases among them were included in the case series of gastrointestinal PEComas. Thus, detailed information regarding these tumors is insufficient (Table 1).

Microscopically, PEComa shows perivascular epithelioid cells arranged radially around the vascular lumens. Spindle cells are usually located at the periphery compared with epithelioid cells. Perivascular epithelioid cells contain a large amount of lipids, and thus, are morphologically similar to lipocyte or lipoblast. Perivascular epithelioid cells have clear to slightly eosinophilic cytoplasm compared with smooth muscle cells. The aforementioned cells demonstrated small, centrally placed, round to oval 
nuclei and small nucleoli, ${ }^{16}$ as in our cases.

Upon immunohistochemial analysis, PEComas are positive for melanocytic markers such as HMB-45, Melan A, and microph- thalmia-associated transcription factor. Among them, HMB-45 is considered to be the most sensitive marker. ${ }^{8}$ In our two cases, the first case was positive for HMB-45, and the second was positive
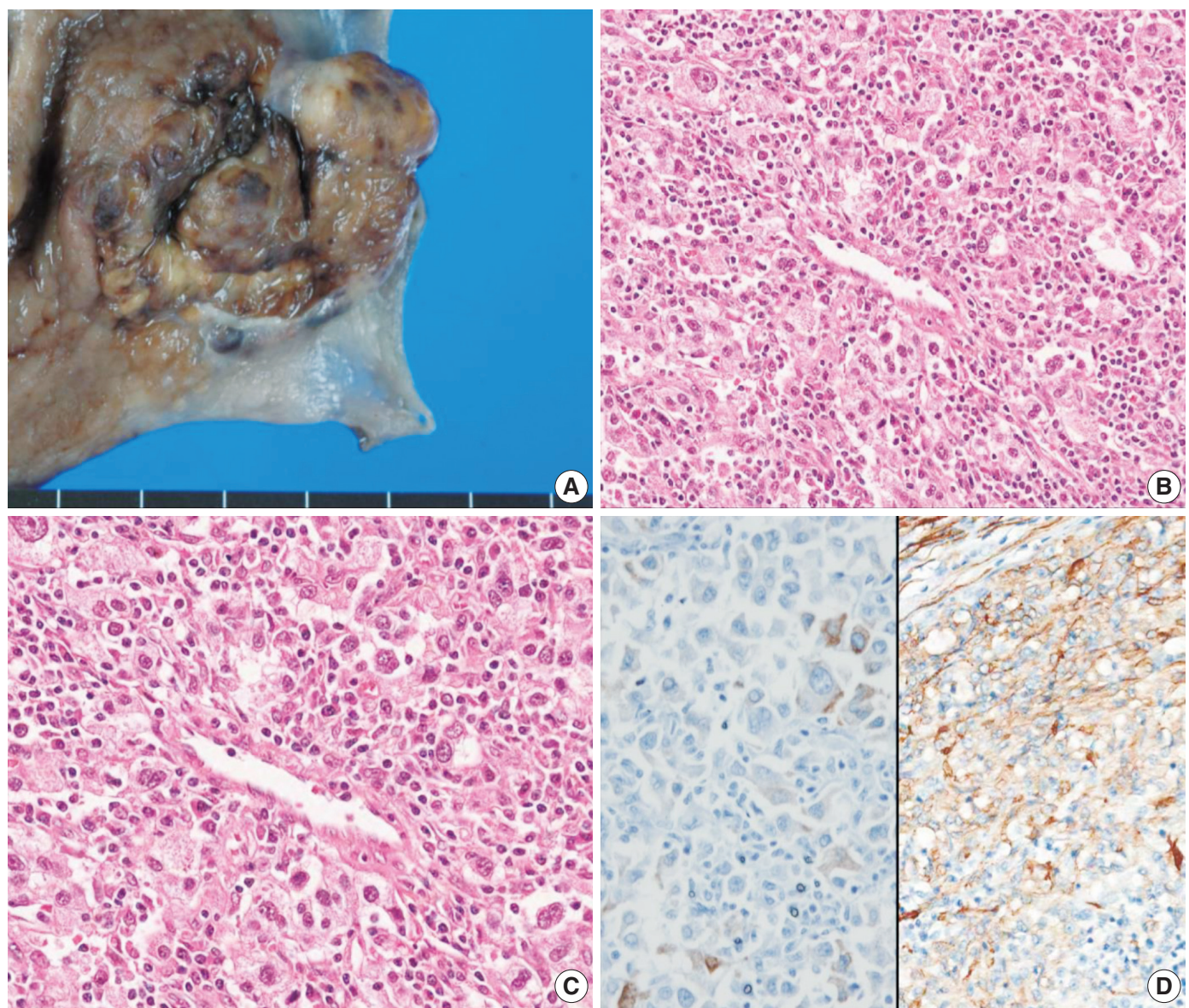

Fig. 2. Case 2. (A) The tumor was a subepithelial lesion involving gastroesophageal junction. (B, C) Microscopically, the tumor was composed of perivascular epithelioid cells with heavy lymphoid cell infiltration. (D) Immunohistochemistry reveals positivity for Melan-A (left) and smooth muscle actin (right).

Table 1. Summary of gastric PEComa cases

\begin{tabular}{|c|c|c|c|c|c|c|c|c|c|c|c|c|c|c|}
\hline \multirow[b]{2}{*}{ Case } & \multirow[b]{2}{*}{ Reference } & \multirow{2}{*}{$\begin{array}{l}\text { Age } \\
(y r)\end{array}$} & \multirow[b]{2}{*}{ Sex } & \multirow{2}{*}{$\begin{array}{l}\text { Size } \\
(\mathrm{cm})\end{array}$} & \multicolumn{5}{|c|}{ Microscopic feature } & \multirow{2}{*}{$\begin{array}{c}\text { Recurrence } \\
\text { or } \\
\text { metastasis }\end{array}$} & \multicolumn{4}{|c|}{$\mathrm{IHC}$} \\
\hline & & & & & $\begin{array}{c}\text { Infiltrative } \\
\text { border }\end{array}$ & $\begin{array}{l}\text { Nuclear } \\
\text { grade }\end{array}$ & $\begin{array}{l}\text { Mitotic } \\
\text { activity }\end{array}$ & Necrosis & Cellularity & & HMB-45 & Melan-A & SMA & Desmin \\
\hline 1 & $\begin{array}{l}\text { Mitteldorf } \\
\text { et al. }{ }^{12}\end{array}$ & 71 & $F$ & 3.0 & - & Moderate & $\begin{array}{l}\text { Low } \\
\text { (1/50 HPF) }\end{array}$ & - & NR & $\begin{array}{r}\text { NED for } \\
19 \mathrm{mo}\end{array}$ & - & + & + & + \\
\hline 2 & $\begin{array}{l}\text { Waters } \\
\text { et al. } .^{13}\end{array}$ & 42 & M & 10.0 & NR & NR & $N R$ & NR & NR & $\begin{array}{l}\text { Metastasis } \\
\text { to liver }\end{array}$ & NR & + & NR & + \\
\hline 3 & $\begin{array}{c}\text { Yamada } \\
\text { et al. } .^{14}\end{array}$ & 39 & M & 7.3 & + & High & $\begin{array}{l}\text { High } \\
\text { (>2/50 HPF) }\end{array}$ & + & NR & $\begin{array}{l}\text { NED for } \\
6 \mathrm{mo}\end{array}$ & + & + & + & + \\
\hline 4 & $\begin{array}{l}\text { Kumar } \\
\text { et al. } .^{15}\end{array}$ & 48 & $\mathrm{~F}$ & 11.5 & NR & High & $\begin{array}{l}\text { High } \\
\text { (20/10 HPF) }\end{array}$ & + & NR & - & - & + & + & NR \\
\hline 5 & Case 1 & 62 & $\mathrm{~F}$ & 4.2 & - & Low & $\begin{array}{l}\text { Low } \\
\qquad(1 / 50 \mathrm{HPF})\end{array}$ & - & Low & $\begin{array}{l}\text { NED for } \\
8 \mathrm{mo}\end{array}$ & + & - & + & + \\
\hline 6 & Case 2 & 67 & M & 5.0 & - & High & $\begin{array}{l}\text { High } \\
\text { (45/50 HPF) }\end{array}$ & - & High & $\begin{array}{l}\text { NED for } \\
7 \mathrm{yr}\end{array}$ & - & + & + & - \\
\hline
\end{tabular}

Case 2-4: malignant gastric PEComas.

IHC, immunohistochemisty; HMB-45, human melanoma black 45; SMA, smooth muscle actin; F, femlae; HPF, high power fields; NR, not recorded; NED, no evidence of disease; M, male. 
for Melan-A. The majority of PEComas are positive for smooth muscle markers, including SMA, desmin, and calponin, and among them, SMA is considered to be the most sensitive, whilst desmin is less sensitive. ${ }^{17}$ Both cases in our study demonstrated positivity for SMA, and the first case showed positivity for desmin. The first case was negative for $\mathrm{CD} 117$ and TFE3; these markers are known to show positivity in a small proportion of PEComas. ${ }^{18}$

Clinically and microscopically, PEComa can be misdiagnosed as epithelioid GIST. Therefore, we re-analyzed 343 cases diagnosed as GIST between 2005 and 2011 in our hospital, including 20 c-kit negative cases. ${ }^{19}$ Of the 343 cases, we found that only a single case showed positivity for Melan- $\mathrm{A}$, and we believe that this case should have been classified as PEComa. Malignant melanoma or clear cell sarcoma should also be considered in the differential diagnosis; however, our second case did not show

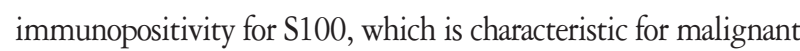
melanoma or clear cell sarcoma.

A consensus regarding the prognostic factors of PEComa has yet to be established because of its rarity. Folpe et al. ${ }^{8}$ concluded that malignant behavior, including recurrence or metastasis of PEComa involving soft tissue and gynecologic organs, is associated with a large size $(>5 \mathrm{~cm})$, frequent mitosis $(>1 / 50 \mathrm{HPF})$, necrosis, infiltrative growth pattern, high cellularity, and high nuclear grade. Hornick and Fletcher ${ }^{17}$ ascertained that malignant behavior was associated with nuclear atypia and pleomorphism. In addition, Doyle et al. ${ }^{9}$ revealed that the aggressive behavior of PEComa of the gastrointestinal tract is associated with a large size $(>6 \mathrm{~cm})$, mitotic count $(>2 / 10 \mathrm{HPF})$, marked cellular atypia, and diffuse pleomorphism.

Among the previously reported four cases of gastric PEComas, three cases displayed histologically malignant features. ${ }^{12-15}$ In our first case, the tumor size was $4.2 \mathrm{~cm}$ and the mitotic count was 1 in 50 HPF. Microscopically, the tumor showed mild pleomorphism. Since there was no evidence of malignant features, the surgeon decided to follow-up without additional treatment. In our second case, the tumor measured $5.0 \mathrm{~cm}$ and the mitotic count was 45 in 50 HPF. Microscopically, the tumor showed marked pleomorphism and high cellularity, and it should have been categorized as a high risk PEComa. However, it was erroneously diagnosed as epithelioid GIST and the patient underwent curative resection only without adjuvant therapy. Fortunately, there was no adverse event during the 7 years of follow-up.

In conclusion, gastric PEComa is a rare neoplasm, but some gastric PEComas show malignant behavior. Therefore, pathologists should include PEComa in the differential diagnosis for gastric subepithelial tumors with epithelioid cell features. Since
PEComas may display faint CD117 immunoreactivity, ${ }^{9} \mathrm{CD} 117$ immunoreactivity alone cannot justify the exclusion of PEComa during the diagnostic process. Its tendency to manifest immunopositivity for melanocytic and smooth muscle markers should warrant pathologists to make a diagnosis with correlation of the patient's clinical information.

\section{Conflicts of Interest}

No potential conflict of interest relevant to this article was reported.

\section{REFERENCES}

1. Pea M, Bonetti F, Zamboni G, et al. Melanocyte-marker-HMB-45 is regularly expressed in angiomyolipoma of the kidney. Pathology 1991; 23: 185-8.

2. Adema GJ, de Boer AJ, Vogel AM, Loenen WA, Figdor CG. Molecular characterization of the melanocyte lineage-specific antigen gp100. J Biol Chem 1994; 269: 20126-33.

3. Pea M, Bonetti F, Zamboni G, Martignoni G, Fiore-Donati L, Doglioni C. Clear cell tumor and angiomyolipoma. Am J Surg Pathol 1991; 15: 199-202.

4. Bonetti F, Pea M, Martignoni G, Zamboni G. PEC and sugar. Am J Surg Pathol 1992; 16: 307-8.

5. Zamboni G, Pea M, Martignoni G, et al. Clear cell "sugar" tumor of the pancreas: a novel member of the family of lesions characterized by the presence of perivascular epithelioid cells. Am J Surg Pathol 1996; 20: 722-30.

6. Hornick JL, Pan CC. PEComa. In: Fletcher CD, Bridge JA, Hogendoorn PC, Mertens F, eds. WHO classification of tumours of soft tissue and bone. 4th ed. Lyon: IARC Press, 2013; 230-1.

7. Folpe AL, Goodman ZD, Ishak KG, et al. Clear cell myomelanocytic tumor of the falciform ligament/ligamentum teres: a novel member of the perivascular epithelioid clear cell family of tumors with a predilection for children and young adults. Am J Surg Pathol 2000; 24: 1239-46.

8. Folpe AL, Mentzel T, Lehr HA, Fisher C, Balzer BL, Weiss SW. Perivascular epithelioid cell neoplasms of soft tissue and gynecologic origin: a clinicopathologic study of 26 cases and review of the literature. Am J Surg Pathol 2005; 29: 1558-75.

9. Doyle LA, Hornick JL, Fletcher CD. PEComa of the gastrointestinal tract: clinicopathologic study of 35 cases with evaluation of prognostic parameters. Am J Surg Pathol 2013; 37: 1769-82.

10. Im S, Yoo C, Jung JH, Choi HJ, Yoo J, Kang CS. Primary perivascular epithelioid cell tumor in the rectum: a case report and review of 
the literature. Pathol Res Pract 2013; 209: 244-8.

11. Shi HY, Wei LX, Sun L, Guo AT. Clinicopathologic analysis of 4 perivascular epithelioid cell tumors (PEComas) of the gastrointestinal tract. Int J Surg Pathol 2010; 18: 243-7.

12. Mitteldorf CA, Birolini D, da Camara-Lopes LH. A perivascular epithelioid cell tumor of the stomach: an unsuspected diagnosis. World J Gastroenterol 2010; 16: 522-5.

13. Waters PS, Mitchell DP, Murphy R, McKenna M, Waldron RP. Primary malignant gastric PEComa: diagnostic and technical dilemmas. Int J Surg Case Rep 2012; 3: 89-91.

14. Yamada S, Nabeshima A, Noguchi H, et al. Coincidence between malignant perivascular epithelioid cell tumor arising in the gastric serosa and lung adenocarcinoma. World J Gastroenterol 2015; 21: 1349-56.
15. Kumar M, Kumar V, Abrina V, Kaur S, Kumar A, Maroules M. Malignant gastric PEComa: a rare malignancy. Am J Cancer Case Rep 2015; 3: 209-14.

16. Folpe AL, Kwiatkowski DJ. Perivascular epithelioid cell neoplasms: pathology and pathogenesis. Hum Pathol 2010; 41: 1-15.

17. Hornick JL, Fletcher CD. PEComa: what do we know so far? Histopathology 2006; 48: 75-82.

18. Argani P, Aulmann S, Illei PB, et al. A distinctive subset of PEComas harbors TFE3 gene fusions. Am J Surg Pathol 2010; 34: 1395406.

19. Lee HE, Kim MA, Lee HS, Lee BL, Kim WH. Characteristics of KIT-negative gastrointestinal stromal tumours and diagnostic utility of protein kinase C theta immunostaining. J Clin Pathol 2008; 61: 722-9. 